\begin{tabular}{|c|c|c|c|c|c|}
\hline & $\begin{array}{l}\text { Primary } \\
\text { coiling } \\
(n=240)\end{array}$ & $\begin{array}{l}\text { balloon- } \\
\text { assisted } \\
(n=68)\end{array}$ & $\begin{array}{l}\text { stent- } \\
\text { assisted } \\
\text { ( } n=287)\end{array}$ & $\begin{array}{l}\text { Stent-and- } \\
\text { balloon } \\
\text { assisted } \\
(\mathrm{n}=\mathbf{2 2}) \\
\end{array}$ & P-value \\
\hline Female, $n(\%)$ & | $187(77.9 \%)$ & $54(79.4 \%)$ & $206(71.8 \%)$ & $17(77.3 \%)$ & 0.327 \\
\hline Age, median(IQR) & $61(55-70)$ & $60(48-70)$ & $62(53-69)$ & $63(53-67)$ & 0.42 \\
\hline Aneurysm size, $\mathrm{n}(\%)$ & & & & & 0.683 \\
\hline. Small $(<11 \mathrm{~mm})$ & |209(87.1\%) & $64(94.1 \%)$ & $255(88.9 \%)$ & $20(90.9 \%)$ & \\
\hline .Large $(11-25 \mathrm{~mm})$ & | $31(12.9 \%)$ & $4(5.9 \%)$ & $31(10.8 \%)$ & $2(9.1 \%)$ & \\
\hline. Giant (>25 mm) & $0(0 \%)$ & $0(0 \%)$ & $1(0.3 \%)$ & $0(0 \%)$ & \\
\hline Wide-Neck aneurysm, $n(\%)$ & | $139(57.9 \%)$ & $42(61.8 \%)$ & $209(72.8 \%)$ & $18(81.8 \%)$ & 0.008 \\
\hline $\begin{array}{l}\text { Time of coil deployment in min, } \\
\text { median (IQR) }\end{array}$ & |15 (9-27) & $25(10-41)$ & $16(7-30)$ & $15(9-32)$ & 0.287 \\
\hline Immediate Raymond Class I, n(\%) & ||102 (42.5\%) & $30(44.1 \%)$ & $95(33.1 \%)$ & $5(22.7 \%)$ & 0.035 \\
\hline One-year Raymond Class I, n(\%) & $82(62.6 \%)^{\infty}$ & $20(42.6 \%) \uparrow$ & $120(75 \%)^{* *}$ & $12(75 \%)^{*}$ & $<0.001$ \\
\hline One-year recurrence, $n(\%)$ & $\mid 17(12.8 \%)^{\text {ceoe }}$ & $14(29.2 \%) \pi$ & $13(8.1 \%)^{* * *}$ & $2(12.5 \%)^{*}$ & $<0.001$ \\
\hline $\begin{array}{l}\text { Device related complications within } 24 \\
\text { hour, } n(\%)\end{array}$ & $3(1.3 \%)$ & 4\%) & $7(2.4 \%)$ & $3(13.6 \%)$ & 0.004 \\
\hline 30-day mortality & |3(1.3\%) & $1(1.5 \%)$ & $8(1.7 \%)$ & $0(0 \%)$ & 0.906 \\
\hline Packing density >30, & $102(42.5 \%)$ & $26(38.2 \%)$ & $135(47 \%)$ & $12(54.5 \%)$ & 0.75 \\
\hline
\end{tabular}

œ missing 109 œ missing 107 tmissing 21 tt missing 20

*missing $6 \quad$ **missing $127 \quad * * *$ missing 126

aneurysm recurrence and complication rates associated with different endovascular techniques.

Methods The prospectively collected data from the SMART registry was interrogated. Only patients with unruptured aneurysms were included in these analyses. Patients were divided into four groups according on the endovascular treatment modality used: group 1 (primary coiling), group 2 (balloon assisted coiling), group 3 (stent assisted coiling), and group 4 (balloon and stent assisted coiling). Baseline characteristics, aneurysm features, packing density, complication and recurrence rates were compared between the groups.

Results Total of 607 patients were included in this study. Of those, 240 were in group 1, 68 in group 2, 287 in group 3 , and 22 in group 4. Median age was 61 (IQR, 53-69), and $75 \%$ were females (table 1). There was no difference in aneurysm size, or duration of coil deployment. Wide neck aneurysms were more prevalent in groups 3 and 4 compared to groups 1 and 2 (group 3;72.8\%, group 4; 81.8\%, group $1 ; 57.9 \%$, and group $2 ; 61.8 \%, \mathrm{P}=0.008)$. While there was no difference in packing density between the groups at initial treatment, at 1-year, complete occlusion (RR class 1) was achieved at a higher rate in groups 3 and $4(75 \%)$ compared to $1(62.6 \%)$ and group $2(42.6 \%)$ $\mathrm{P}<0.001$. There was higher rate of device related complications within 24 hours in group 4 compared to groups 1,2 and 3 (group 4 13.6\%, groups 1,2 and $3 ; 1.3 \%, 4.4 \%$, $2.4 \%$ respectively, $\mathrm{P}=0.004)$.
Conclusions In patients with unruptured intracranial aneurysms, the use of primary coiling and balloon assisted coiling was associated with similar packing density to stent or stent plus balloon assisted coiling, though with lower rates of aneurysm obliteration at 1 year. Combined stent and balloon assisted coiling was associated with higher rates of immediate complications. Further prospective studies are warranted to confirm our findings.

Disclosures S. Al Kasab: None. E. Almallouhi: None. M. Anadani: None. M. Sattur: None. A. Spiotta: None.

\section{E-045 INTRAVASCULAR ULTRASOUND FOR EVALUATING VENOUS SINUS STENOSIS IN PATIENTS WITH PSEUDOTUMOR CEREBRI/IDIOPATHIC INTRACRANIAL HYPERTENSION}

${ }^{1}$ A Nicholson*, ${ }^{2} \mathrm{C}$ Woods, 'S Taylor, ${ }^{1} E$ Guilliams, 'f Cuoco, ${ }^{1} B$ Klein, ${ }^{1} D$ Summers, ${ }^{1} \mathrm{M}$ Witcher, ${ }^{1} \mathrm{E}$ Marvin, ${ }^{1} \mathrm{~J}$ Entwistle. ${ }^{1}$ Neurosurgery, Carilion Clinic, Roanoke, VA; ${ }^{2}$ Virginia Tech Carilion School of Medicine, Roanoke, VA

\subsection{6/neurintsurg-2019-SNIS.120}

Introduction/Purpose Imaging and pressure readings in patients with pseudotumor cerebri (PTC)/idiopathic intracranial hypertension (IIH) are traditionally done using magnetic resonance imaging (MRI) and minimally invasive catheterbased manometry. These measurements are important to 


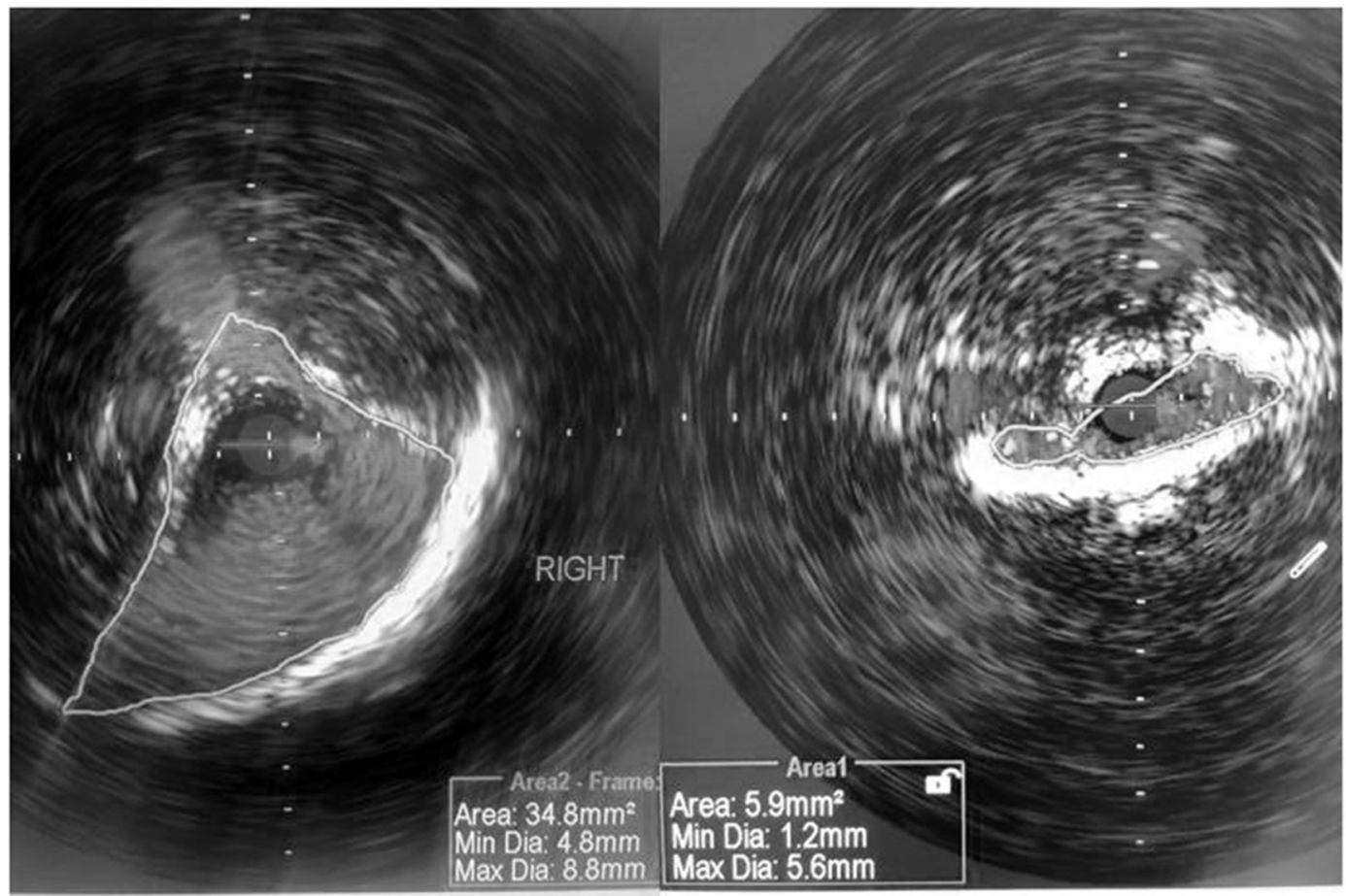

Abstract E-045 Figure 1 Intravascular ultrasound (IVUS) images demonstrating normal transverse sinus (a) and an area of over $80 \%$ stenosis at the transverse-sigmoid sinus junction on the same side (b). This patient had a corresponding pressure gradient of over $40 \mathrm{mmHg}$ on manometry, and anopening pressure on LP of greater than $55 \mathrm{~cm} \mathrm{H}_{2} \mathrm{O}$.

rule out other diagnoses, deciding where to place a stent, and evaluating patients post-stent. However, the intravascular ultrasound (IVUS) is a newer technology that needs to be further evaluated for its potential as a replacement for these current methods. IVUS can be used to both measure the degree of stenosis of the vessel as well as the pressure gradient through its functional flow reserve (FFR) measurement. By comparing the measurements from IVUS to those from both MRI and manometry, the use of this newer technology in diagnosing and treating IIH can be further understood.

Materials and methods This study is a retrospective chart review consisting of 10 consecutive patients with IIH who underwent venous sinus stenting at our institution. All patients had measurements taken via MRI, manometry, FFR pressure measurements and IVUS. We plan to compare the IVUS measurements to both MRI and pressure measurements to assess the degree of stenosis in these patients. Post-stenting follow up data is available between 3-9 months.

Results Initial analysis demonstrates a strong correlation between venous stenosis seen on IVUS and pressure gradients. This holds up even in patients with little to no stenosis seen on MRI. Final statistical analysis is in process and will be completed in time for the conference.

Conclusion As stenting becomes a more popular course of treatment for IIH patients, it is important that the technology used for these procedures is accurate. This study will help expand the literature surrounding the use of IVUS as a diagnostic tool for patients with IIH.

Disclosures A. Nicholson: None. C. Woods: None. S. Taylor: None. E. Guilliams: None. J. Cuoco: None. B. Klein: None. D. Summers: None. M. Witcher: None. E. Marvin: None. J. Entwistle: None.

\section{E-046 VENOUS SINUS STENTING AS A TREATMENT APPROACH IN PATIENTS WITH IDIOPATHIC INTRACRANIAL HYPERTENSION AND ENCEPHALOCELES}

${ }^{1} \mathrm{G}$ Drocton, III, ${ }^{1} \mathrm{~A}$ Copelan*${ }^{*},{ }^{1} \mathrm{M}$ Amans, ${ }^{1} \mathrm{R}$ Khangura, ${ }^{1} \mathrm{~J}$ Villanueva-Meyer, ${ }^{2} \mathrm{~L}$ Eisenmenger, ${ }^{1} \mathrm{~K}$ Meisel. 'UCSF Medical Center, San Francisco, CA; ${ }^{2}$ Department of Radiology, UW Health University Hospital, Madison, WI

\subsection{6/neurintsurg-2019-SNIS. 121}

Introduction Brain herniations, or encephaloceles, into arachnoid granulations in dural venous sinuses have rarely been reported in the literature. Prominent arachnoid granulations by themselves may be a cause of idiopathic intracranial hypertension (IIH) by obstructing sinus venous flow as well as causing flow turbulence that may present itself clinically with pulse synchronous tinnitus. This unique type of encephalocele combined with idiopathic intracranial hypertension (IIH) is an unreported occurrence and the optimal management in this rare subselect group of patients is unknown.

Materials and methods A retrospective review of 256 cases of IIH over a three-year span (March 2016 to March 2019) was performed at our institution. Imaging from the cases was reviewed by two trained diagnostic neuroradiologists assessing for the presence and location of dural sinus arachnoid granulations and/or encephaloceles based on MRI. Those patients that were found to have arachnoid granulations and concomitant encephalocele were documented and a clinical chart review was performed.

Results Of the 256 reviewed cases, 15 were found to have encephaloceles on MR imaging. 2 of the 15 cases had medically refractory IIH and underwent venous sinus stenting for management of their symptoms. Patient A is a 44 yearold female with symptoms of pulsatile tinnitus, papilledema, 